\title{
NUTRITION AND CYTOKINE ACTION
}

\author{
R. F. GRIM B LE
}

Human Nutrition Department, Southampton University Medical School, Southampton SO9 3TU

\section{CONTENTS}

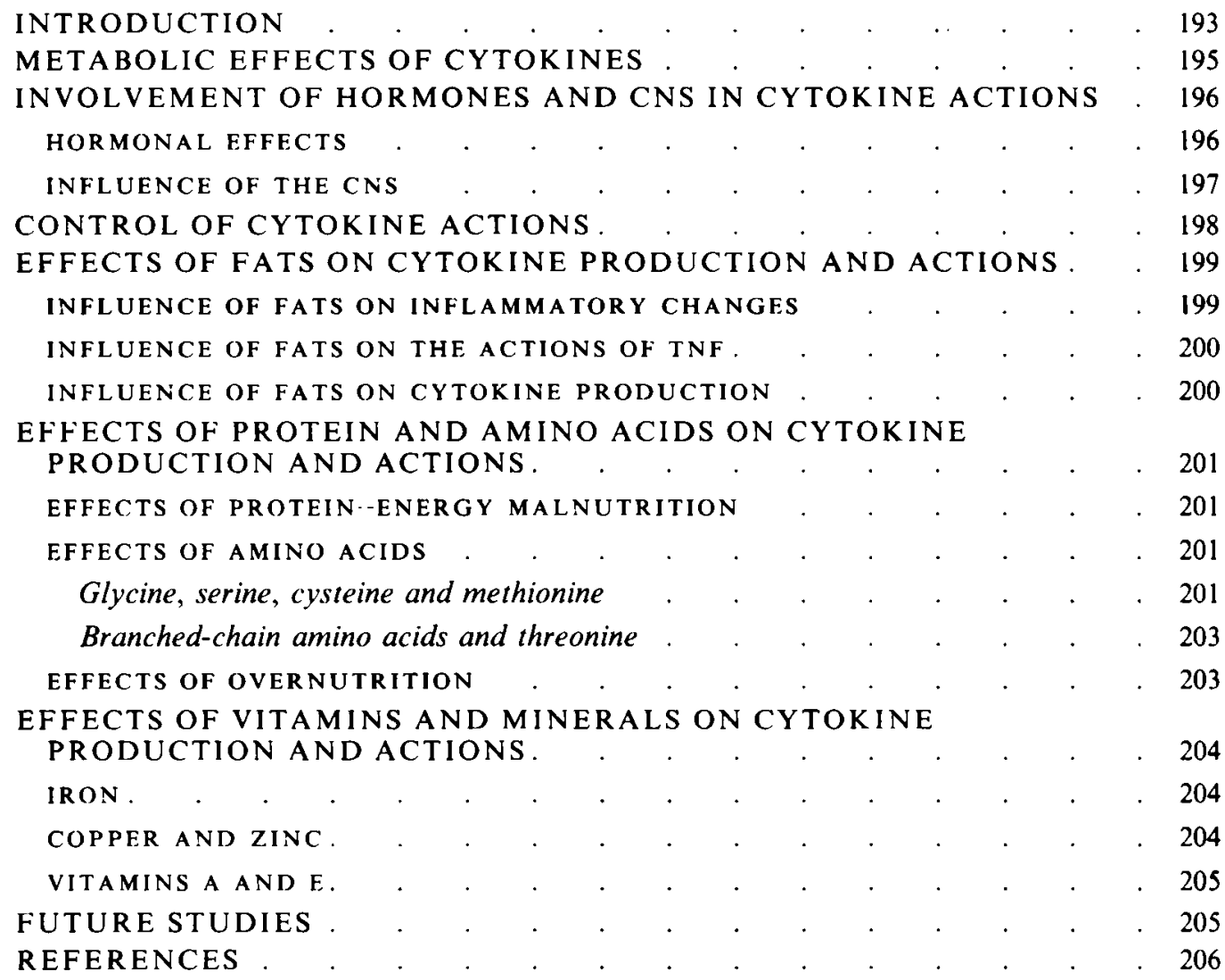

\section{INTRODUCTION}

Cytokines are a diverse range of polypeptides produced in response to inflammatory stimuli. Early studies suggested that they were the products of phagocytic immune cells; however, it has recently become apparent that $\mathrm{T}$ and $\mathrm{B}$ lymphocytes, fibroblasts and various endothelial cells are also capable of synthesizing cytokines (Dinarello, 1986; Miossec \& Ziff, 1986). While the early studies suggested that cytokine production was part of the non-specific immune response to invasion by parasites and bacteria (Beutler \& Cerami, 1987; Van der Meer et al. 1988), subsequent research showed that cytokines are also produced in inflammatory diseases such as Crohn's disease and rheumatoid arthritis (Larrick \& Kunkel, 1988; Guerne et al. 1989; Mahida et al. 1989), which do not involve 


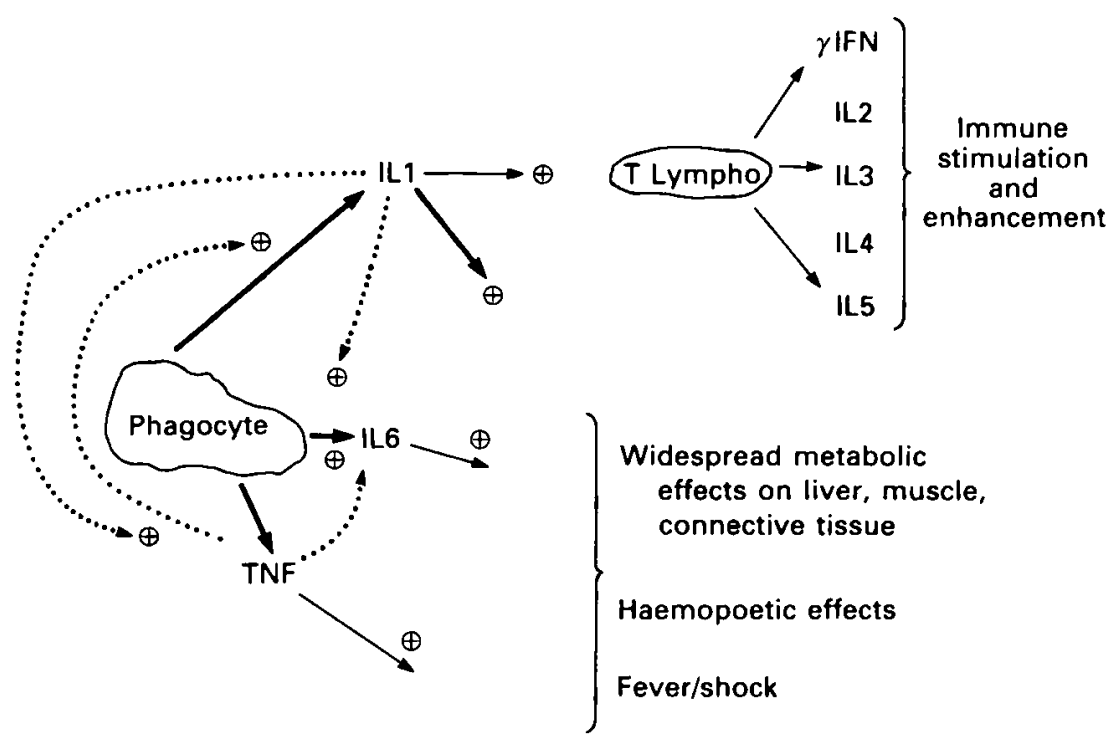

Fig. 1. General scheme for cytokine-mediated changes in inflammatory states and stimulation of cytokine production by cytokines. $\gamma$ IFN, $\gamma$ interferon; ILI, interleukin $1 \alpha$ and $\beta$; IL 2-6, interleukins 26; TNF, tumour necrosis factor $\alpha$ and $\beta$; T lympho, T lymphocyte. Dotted lines indicate a stimulatory effect.

pathogens. They are also produced in conditions of physiological change such as during the menstrual cycle or after strenuous exercise (Cannon \& Kluger, 1983; Cannon \& Dinarello, 1985; Cannon et al. 1989). An increasing number of cytokines are being identified and characterized. Those which have been studied in most detail are interferons $\alpha$ and $\gamma$, interleukins 1-6 (IL1-6), and tumour necrosis factors $\alpha$ and $\beta$ (TNF). Some, namely interferons $\alpha$ and $\gamma$ and IL2-4, stimulate and modify immune function (Fig. 1). Others, IL1 and 6 , and TNF $\alpha$ and $\beta$, not only influence the immune system, but also initiate profound changes in energy, protein and trace element metabolism (Dinarello, 1984 $a$; Cousins \& Leinart, 1988; Feingold et al. 1989).

As indicated in Fig. 1, cytokines are potent stimulators for the production of cytokines (Dinarello et al. 1986; Le et al. 1987; Old, 1987; Heinrich et al. 1990). Thus, patients and animals exposed to an inflammatory stimulus may experience a cascade of cytokine production.

IL $1 \alpha$ and $\beta$, IL6 and TNF $\alpha$ and $\beta$ may initiate many of the metabolic effects encountered, to a greater or lesser extent, in a wide range of inflammatory diseases (Fig. 2). The overall effect is a redistribution and enhancement in the turnover of tissue components (Dinarello, 1984 b; Bagby et al. 1988; Charters \& Grimble, 1989; Flores et al. 1989; Fong et al. 1989).

Many studies have shown that the immune system is sensitive to nutritional factors (Gross \& Newberne, 1980). Furthermore many of the metabolic effects which are encountered during inflammation, and are initiated by cells of the immune system, have nutritional implications. These are summarized in Table 1. Despite these phenomena, nutritional aspects of cytokine biology have received little attention. The present review will examine what is known of the interactions between nutrition and cytokine biology, and indicate future avenues for research.

Nutritional factors may theoretically act at two main levels: first in influencing synthesis and release of cytokines, and second by affecting the direct and indirect actions on target 


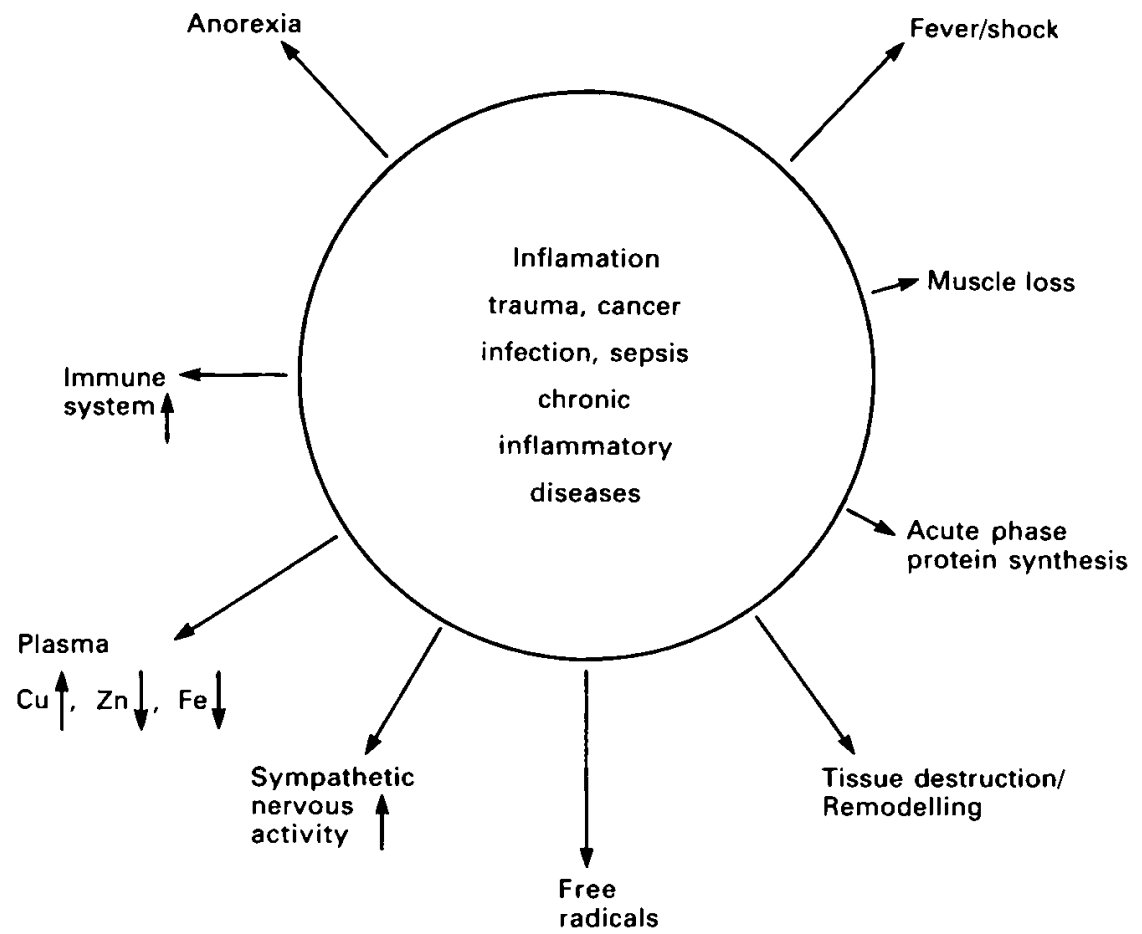

Fig. 2. Metabolic effects of inflammatory disease.

Table 1. Nutritional Implications of Inflammation

\begin{tabular}{ll}
\hline \hline Response & Nutritional implication \\
\hline Fever & Energy requirements \\
Acute-phase proteins & Protein \\
(1) Metaliothionein & Zinc, glycine, serine, methionine, cysteine \\
(2) Caeruloplasmin & Copper \\
(3) C-reactive protein & Glycine, serine \\
Connective tissue remodelling & Glycine, ascorbic acid \\
Haemopoiesis & Protein, glycine, iron, folate, vitamin $\mathbf{B}_{12}$ \\
Eicosanoid production & Essential fatty acids \\
Free radicals & Vitamin E, glycine, cysteine, riboflavin \\
\hline \hline
\end{tabular}

tissues and subsequent responses. IL1 and 6 and TNF bring about their metabolic effects by direct interaction with tissues, and indirectly via stimulation of the endocrine and central nervous (CNS) systems. These systems interact on each other in bringing about the indirect actions of cytokines (Del Rey et al. 1987; Dao et al. 1988; Sherry \& Cerami, 1988; Beutler \& Cerami, 1988a).

\section{METABOLIC EFFECTS OF CYTOKINES}

Although IL1, IL6 and TNF are structurally different, the metabolic effects of IL1 and TNF are strikingly similar. These characteristics have been reviewed in detail elsewhere (Beutler \& Cerami, 1986, 1988 b; Dinarello, 1986, 1987). ILI and TNF are thought to bring 
about muscle protein loss, lipolysis, enhanced gluconeogenesis, connective tissue remodelling and redistribution of tissue zinc, iron and copper, although studies with recombinant-produced individual cytokines have indicated continuing uncertainty about the exact identity of the cytokines responsible for some of these effects (Moldawer et al. 1987). The effects of IL6 on these processes has yet to be reported in detail. Some studies, however, suggest that this cytokine does, like others, promote fever and acute-phase protein synthesis by the liver (Neta et al. 1988; Ramadori et al. 1988). IL6 may in fact be the main cytokine that initiates hepatic acute-phase protein synthesis (Castell et al. 1989; Heinrich et al. 1990). Evidence is accumulating, however, that individual cytokines promote the production of different profiles of acute-phase proteins (Mortensen et al. 1988). For example, in vitro studies on the rat hepatoma cell line Fao showed that while recombinant human IL6 produced a sixfold increase in $\beta$-fibrinogen mRNA, recombinant human IL1 $\beta$ or TNF $\alpha$ had little effect. However, a twentyfold increase in $\alpha-1$-acid glycoprotein mRNA occurred in response to TNF $\alpha$ or $\mathrm{IL1} \beta$, while IL6 had little effect (Andus et al. 1988). It is unclear if these observations are relevant to understanding acute-phase protein changes in inflammatory diseases. It is likely that release of a range of cytokines occurs in many conditions. The nature of the profile of these molecules, produced in specific inflammatory states, needs further study in order to understand the acute-phase response.

The metabolic events initiated by cytokines are accompanied by elevated circulating levels of catecholamines, glucocorticoids and glucagon, varying concentrations of insulin and by increased prostaglandin (PG) and leukotriene (LT) synthesis within a number of target tissues. In the case of brain, muscle and connective tissue, PG predominantly are elevated. In cells of the immune system both PG and LT are raised (Dinarello, 1984 $b$; Spinas et al. 1986; Douglas \& Shaw, 1989).

\section{INVOLVEMENT OF HORMONES AND CNS IN CYTOKINE ACTIONS}

\section{HORMONAL EFFECTS}

The hormonal changes provide the means of facilitating, coordinating and controlling the metabolic actions of cytokines. Such control is particularly important in severe inflammatory conditions which arise from physical trauma and invasion by pathogens. In these situations two things are required: first that the activity of the immune system is enhanced, and second that substrate for nourishing the system and bringing about tissue repair be provided from internal sources, since the ability of the animal to elicit nourishment from the external environment will be impaired.

Substrate is provided from fat, amino acid and carbohydrate metabolism (Mészáros et al. 1987; Douglas \& Shaw, 1989). Bagby et al. (1988) demonstrated marked increases in glucose uptake into macrophage-rich tissues in animals treated with endotoxin, ILI and TNF. Plasma triglycerides increase in many inflammatory conditions. This is undoubtedly due to the primary and secondary actions of cytokines. The increase is thought to occur by combined events within adipose tissue and liver. Increased adipose tissue lipolysis occurs as the result of the actions of cytokines and catecholamines. The free fatty acids so generated are re-esterified in the liver and secreted back into the circulation. A very small proportion of the lipids synthesized by the liver come from de novo fatty acid synthesis from glucose (Evans et al. 1989; Feingold et al. 1989). Cytokines such as IL1 and TNF inhibit adipose tissue lipoprotein lipase $(E C 3.1 .1 .34)$, thus preventing re-entry of triglycerides (Evans \& Williamson, 1988; Argiles et al. 1989a). Lipid substrate is, thus, available for use elsewhere. 
Studies conducted by Newsholme et al. (1985) and Newsholme \& Newsholme (1989) aimed at identifying the interactions between substrates available for cells involved in the immune response indicate the importance of glutamine, glucose and oleate. The relative rates of utilization of oleate, glutamine and glucose by murine peritoneal macrophages in culture were $1: 4: 25$ on a molar basis. The three substrates contributed 22,24 and $54 \%$ to total ATP production. Glucose and oleate utilization were enhanced by the presence of glutamine in the medium, while oleate did not affect utilization of glucose or glutamine. Further studies are required to examine how the intricate metabolic relationships between these three substrates change in macrophages, when stimulated by inflammatory agents and conditions.

Elevated concentrations of the catabolic, counter-regulatory hormones (cortisol, glucagon, adrenalin, and growth hormone), encountered in severe inflammation, ensure that gluconeogenesis and lipolysis are maintained at a high level, and that amino acid substrate is provided, mainly from muscle proteolysis but also from the muscle glutamine pool (Rennie et al. 1986; Millward et al. 1989), to nourish the immune system and support tissue repair. This topic has been covered in detail by Evans et al. (1989).

\section{INFLUENCE OF THE CNS}

The production of catabolic, counter-regulatory hormones is enhanced by a combination of increased activity of the sympathetic nervous system and formation of releasing factors such as corticotrophin-releasing factor (CRF), which arise as the result of the actions of cytokines on the CNS.

Interactions between cytokines and the CNS not only enhance production of the hormones which increase substrate flow from fat, protein and carbohydrate sources to the immune system, but also lead to the production of fever and anorexia and ultimately to a reduction of cytokine production. CRF may be important in all three of these activities (Fig. 3). The mechanism of fever has been reviewed by Dinarello et al. (1988). In essence circulating cytokines may act on an area of the hypothalamus called the organum vasculorum laminae terminalis (OVLT) which lies close to the preoptic-anterior hypothalamus. PG are subsequently produced from endothelial cells of the OVLT, and either directly stimulate the temperature-sensitive neurones nearby that induce fever or stimulate production of neurotransmitters which act likewise. Studies which showed that not only cyclo-oxygenase inhibitors but also cyclohexamide could block fever suggested that these transmitters may be peptides.

The ability of CRF to induce fever when given intracerebrovascularly (Rothwell, 1989), and the appearance of CRF mRNA in the hypothalamus in response to ILl (Uehara et al. 1987), suggested that CRF may be one such transmitter. CRF may also be involved in the anorexia produced by cytokines, although the precise mechanism remains to be determined. In an elegant study, Uehara et al. (1989) were able to halve the anorexic effect of ILl by immuno-neutralization of CRF in the brain. Other mechanisms may be involved in anorexia apart from increased CRF levels in the hypothalamus. Patients receiving endotoxin showed rapid elevations of $\mathrm{ACTH}$, cortisol and catecholamines. The hormonal response was blocked by pretreatment with ibuprofen, although the increase in circulating TNF $\alpha$ was unaffected (Revhaug et al. 1988). These mechanisms, however, may not be directly related to PG, for while blood glucose and body temperature responses to endotoxin are prevented by cyclo-oxygenase inhibitors, loss of appetite is unaffected (McCarthy et al. 1984). Direct actions of cytokines on the appetite centres may occur, as ILl and TNF alter the firing rate of glucose-sensitive neurones in the lateral hypothalamus (Plata-Salamán et al. 1988). Cytokines may also affect peripheral signals to the feeding 


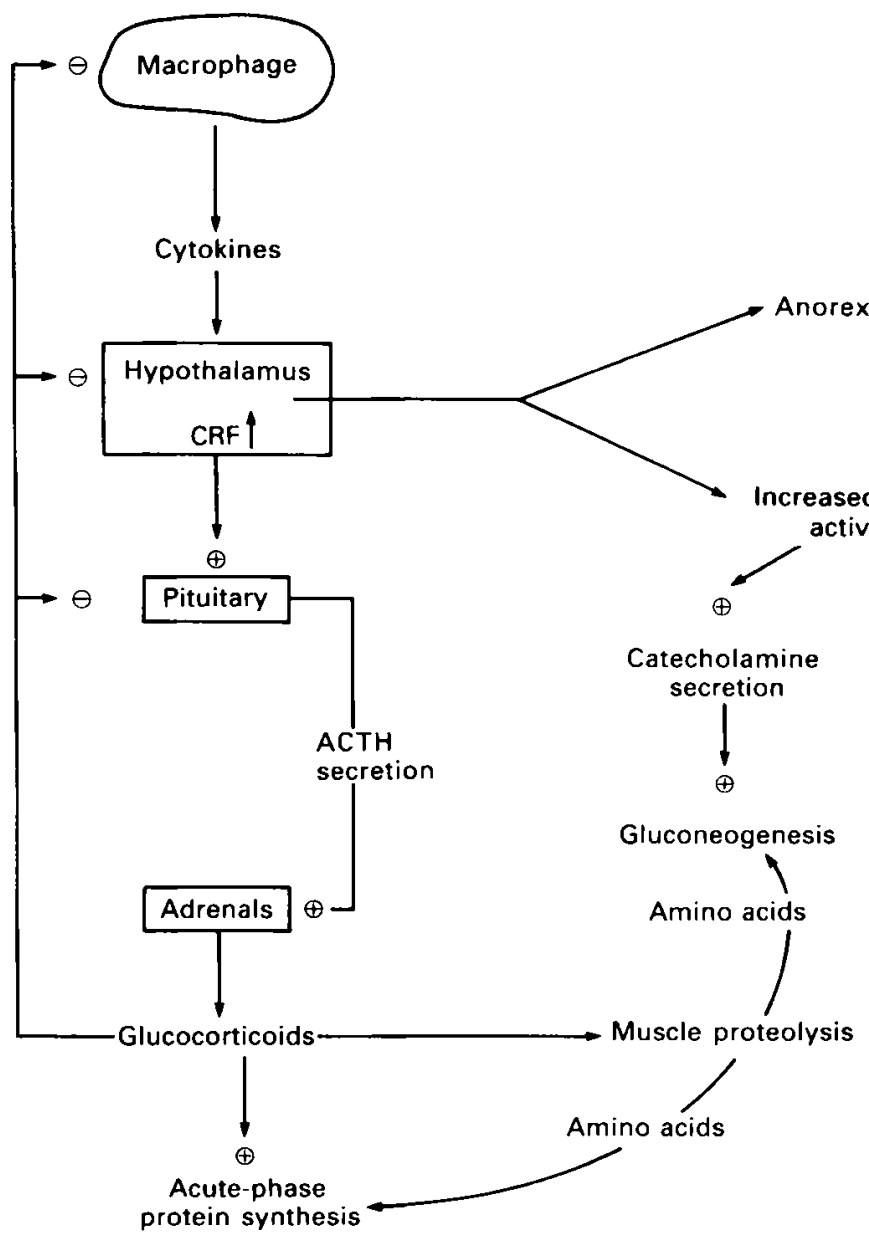

Fig. 3. The role of corticotrophin-releasing factor (CRF) in the metabolic effects of cytokines. ACTH, adrenocorticotrophic hormone; SNS, sympathetic nervous system.

centres, since TNF leads to a transient inhibition of gastric emptying (Patton et al. 1987).

\section{CONTROL OF CYTOKINE ACTIONS}

Paradoxically, cytokines, although essential to the recovery process, are lethal in high doses (Cerami \& Beutler, 1988). This property, together with the fact that a cascade phenomenon exists whereby cytokines can stimulate each other's production (Dinarello et al. 1986; Warner et al. 1987), makes it imperative that mechanisms exist for down-regulating their production and actions (Grimble, 1989). The glucocorticoid response initiated by CRF may be important in down-regulating cytokine production since a number of studies have shown that glucocorticoids and PG are each able to inhibit cytokine production. The biological significance of these effects remains to be determined. While glucocorticoids have been shown to be effective in vivo (Staruch \& Wood, 1985; Bochner et al. 1987; Waage et al. 1987), PG effects have only been demonstrated in vitro. Furthermore, PG and LT have a common precursor, so that production of both might be expected in response to a 
cytokine stimulus. Products of the lipoxygenase (EC 1.13.11.12) pathway stimulate cytokine production in vitro (Rola-Pleszczynski \& Lemaire, 1985). In vivo studies suggest that production of LT has the more potent eicosanoid effect, as discussed later. The biological relevance of these studies remains to be determined.

Cytokines themselves may initiate events which reduce biological activity. This may occur by down-regulation of receptors, and synthesis of inhibitory proteins. Reduced binding of TNF $\alpha$ has been observed in a number of cell lines exposed to phorbol myristate acetate, a compound which mimics IL1 action at the cell surface (Holtmann \& Wallach, 1987). The inhibition of binding is prevented by pretreatment of the cell lines with protein kinase $C(E C 2.7 .1 .37)$ inhibitors, thus implicating protein phosphorylation in the downregulation process (Unglaub et al. 1987).

The discovery of a protein of $40000-60000$ molecular weight in the urine of patients with fever, which is capable of inhibiting the actions of cytokines, indicates that the production of inhibitory proteins may be an integral part of the process by which the actions of cytokines are controlled (Liao \& Rosenstreich, 1983).

\section{EFFECTS OF FATS ON CYTOKINE PRODUCTION AND ACTIONS}

\section{INFLUENCE OF FATS ON INFLAMMATORY CHANGES}

The interactions between nutrients, inflammation and cytokine biology have received the greatest attention in the area of dietary fats (Wan et al. 1988; Hwang, 1989). Interest has arisen primarily because of the known ability of fats to modify cell membrane structure and function, particularly in their ability to alter eicosanoid metabolism. Modification arises from dietary-induced changes in fatty acid composition of the phospholipids within cell membranes. In particular, changes in the relative abundance of arachidonic acid (AA) which gives rise to PG and LT of the 2 and $4 n-6$ series respectively, and eicosapentaenoic acid (EPA) which is the precursor of PG and LT of the 3 and $5 n-3$ series, are likely to be important. PG and LT of the 3 and 5 series have, in general, lower biological activity than those of the 2 and 4 series. The two essential fatty acids, linoleic and $\alpha$-linolenic, act as precursors for AA and EPA respectively. EPA occurs in abundance in fish oils.

A number of experimental and clinical studies have shown that lipids can modify inflammatory changes in situations in which cytokine production is likely. The modifications can be brought about by changing both the composition and quantity of fat in the diet. Inflammatory diseases such as rheumatoid arthritis and psoriasis (Kremer et al. 1987; Bittiner et al. 1988) are ameliorated by ingestion of EPA-rich fish-oil preparations. Many of the metabolic effects of burn injury in experimental animals can be lessened by previous ingestion of fish oil (Trocki et al. 1987). Wan \& Grimble (1987) and Brown et al. (1987) demonstrated that fish oil and coconut oil (a fat with a low concentration of linoleic acid) suppressed tissue protein changes in response to Escherichia coli endotoxin. Cerra et al. (1988) showed that fish oil protected rats from the lethal effects of $E$. coli endotoxin caused by caecal ligation and puncture. Alexander et al. (1986) reported a reduction in C3 complement protein and in the elevation of metabolic rate following burn injury in guineapigs, when the animals were raised on diets enriched with EPA. The inflammatory response to burn injury in guinea-pigs was affected by the quantity of fat fed. Animals fed on safflower oil as $30-50 \%$ of energy showed a greater loss of muscle and elevation of transferrin than animals given 0 or $15 \%$ of their dietary energy as safflower oil. 


\section{INFLUENCE OF FATS ON THE ACTIONS OF TNF}

The exact extent to which the suppressive effects of fats rich in EPA, or of variable linoleic acid content, are due to modified action of endogenously generated cytokines on target tissues, or due to an altered response to the inflammatory stimulus, is unclear in these studies. Either possibility might occur because of the involvement of eicosanoids in the actions of cytokines on target tissues and because of the ability of PG to inhibit, and LT to stimulate, cytokine production in vitro. These possibilities are demonstrated in a number of studies. Bibby \& Grimble (1990a) showed that rats which were fed on maize oil, and treated with high and low doses of recombinant human TNF, experienced a loss of tibialis muscle protein and a gain of liver protein. In rats fed on coconut oil only the high dose of TNF had an effect on tissue protein. These workers also demonstrated that while hypothalamic minces taken from rats fed on maize oil produced $\mathrm{PGE}_{2}$ in response to a range of doses of TNF or endotoxin, those from rats fed on coconut oil could not (Bibby \& Grimble, 1990b). Fats can, thus, alter the target tissue responsiveness to TNF.

\section{INFLUENCE OF FATS ON CYTOKINE PRODUCTION}

A study conducted by Endres et al. (1989) showed that dietary fat is able to modify cytokine production. In the study, fish oil supplements fed for 8 weeks to healthy volunteers reduced the ability of monocytes to produce ILl $\alpha$ and $\beta$ and TNF in response to endotoxin stimulation. After 6 weeks of dietary supplementation, a 20-40\% reduction occurred in cytokine production. The inhibitory effect of fish oil persisted for 10 weeks beyond the end of the supplementation period, and intensified in the case of ILl $\beta$. The mechanism of the effect is intriguing. Fatty acid analysis of total membrane phospholipids revealed a fivefold increase in EPA and a $40 \%$ reduction in AA concentration by the end of the supplementation period. However, 10 weeks beyond this period EPA levels had fallen to presupplementation values. The precise phospholipid pool which releases AA and EPA in response to cytokines is unclear. It was noted, however, that prolonged exposure of rats to endotoxin brings about depletion of the phosphoinositol (PI) pool in membranes, leaving other pools unaffected (Roger et al. 1989). As the PI pool is a minor component of total membrane phospholipids, crucial changes which may have occurred in the PI pool would have been masked by alteration in other phospholipids. The changes in EPA and AA concentration observed in the study would have resulted in the much less inflammatory PG and LT of the 3 and $5 n-3$ series being formed on contact with the endotoxin stimulus. Thus, another intriguing facet of the study of Endres et al. (1989) is that enhanced cytokine production might have been expected if the inhibitory effects of the $\mathrm{PGE}_{2}$ on cytokine production which have been demonstrated in vitro (Van der Meer et al. 1988) have in vivo significance. This was clearly not the case, suggesting that the stimulatory influence of LT on cytokine release, which has also been demonstrated in vitro, has in vivo significance. The reduced cytokine production demonstrated by Endres et al. (1989) may, therefore, have been due to generation of LT of reduced biological potency.

Further doubt is thrown on the in vivo significance of the ability of $\mathrm{PGE}_{2}$ to inhibit cytokine production by a study in which acetylsalicylate failed to affeci the ability of mice to produce TNF in response to Listeria monocytogenes (Fung et al. 1988). Some in vitro studies also support the view that LT, and not PG, are the biologically significant eicosanoids effecting cytokine production. While ibuprofen had no effect on leukocytic pyrogen release from human monocytes stimulated with Staphylococcus albus. ETYA and BW755C, both of which inhibit LT production in vivo, were able to do so (Dinarello et al. 1984). Further studies were clearly needed into the manner by which eicosanoids affect cytokine production. 


\section{EFFECTS OF PROTEIN AND AMINO ACIDS ON CYTOKINE PRODUCTION AND ACTIONS}

\section{EFFECTS OF PROTEIN-ENERGY MALNUTRITION}

Neumann et al. (1975), studying immunological responses of normal and malnourished Ghanaian children, provided the first clue that cytokines might be influenced by protein-energy malnutrition. In the study, malnourished children showed four times the amount of infection and a $20 \%$ increase in parasitic infestation rates experienced by normal children, yet had lower circulating concentrations of the acute-phase protein, C3 complement. The opposite would be expected since infection and infestation provide a potent stimulus by cytokine production. A number of animal studies subsequently showed that protein deficiency reduces the metabolic responses to endotoxin. Reduced febrile responses have been reported in rats and rabbits. Protein deficiency also reduces the ability of monocytes to produce cytokines (Kauffman et al. 1986). Monocytes from children with protein energy malnutrition showed reduced ILl activity when exposed to endotoxin (Bhaskaram \& Sivakumar, 1986). Earlier, Keenan et al. (1982) reported a reduced ability of leukocytes from malnourished patients to produce cytokines capable of causing leukocytosis in a rat bioassay. Since ILI, TNF and IL6 are all capable of producing leukocytosis and fever, it is not possible to say which of the cytokines showed defective production. When the malnourished patients were given protein in the range of $30-120 \mathrm{~g} / \mathrm{d}$, the bioassay revealed an improvement in the ability of leukocytes from the patients to produce cytokines which was almost linearly related to the protein intake. The latter two studies help to shed light on the phenomenon, reported by Alleyne et al. (1977), of asymptomatic infective disease in children with severe malnutrition who developed fever on nutritional rehabilitation.

\section{EFFECTS OF AMINO ACIDS}

\section{Glycine, serine, cysteine and methionine}

While it has been demonstrated that the provision of dietary protein might improve cytokine production and actions in previously malnourished individuals, it is unclear whether inflammatory states, which produce profound alterations in tissue protein metabolism, might change the requirements for certain amino acids. The metabolically interrelated amino acids, glycine, serine, methionine and cysteine (Fig. 4), occur in high concentrations in many proteins synthesized in increased amounts during infection, trauma and in chronic inflammatory diseases (Table 2). It is interesting to note that these four amino acids make up (\%): metallothionein 56 , serum amyloid A 25 , collagen 38 , C-reactive protein 21 . The suggestion that inflammation may impose additional requirements for specific amino acids is supported by findings from a number of studies.

In vitro studies have demonstrated the essentiality of glycine, cysteine and methionine for maintenance of secretory protein production from hepatocytes (Hutson et al. 1987). Dogs treated with endotoxin showed a $75 \%$ fall in hepatic free glycine content (Liu \& Zhang, 1985). Volunteers exposed to sandfly fever showed large decreases in plasma glycine concentration (Wannemacher, 1977). During the early flow phase of the response to multiple trauma, patients showed significant depressions in concentrations of non-essential amino acids, while essential amino acids were largely unaffected. Alanine, glycine, glutamine and proline were reduced by $26,49,36$ and $42 \%$ (Jeevanandam et al. 1989); these changes were explained in terms of an increase in urinary excretion. Other explanations, however, are possible since essential amino acid levels did not fall despite similar increases in urinary excretion rates. 


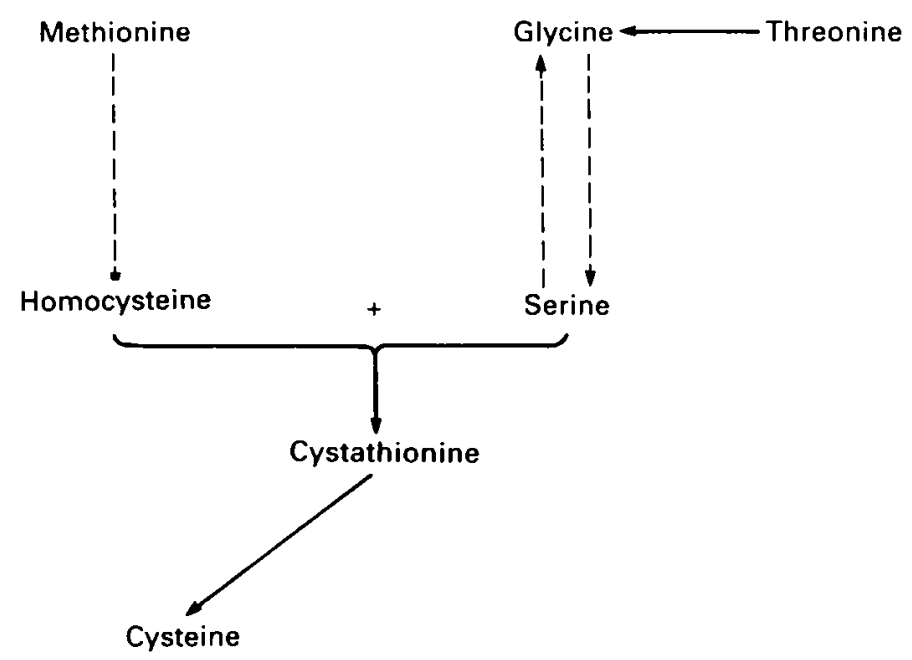

Fig. 4. Links between glycine, serine, threonine, methionine, and cysteine metabolism.

Table 2. Amino acid composition of human proteins (\% of residues) showing changed synthetic rates during inflammation

\begin{tabular}{|c|c|c|c|c|}
\hline & Glycine & Serine & $\begin{array}{l}\text { Methionine } \\
\text { + cysteine }\end{array}$ & Total \\
\hline \multicolumn{5}{|l|}{$\begin{array}{l}\text { Increased synthesis during } \\
\text { inflammation }\end{array}$} \\
\hline $\mathrm{C}_{3}$ complement & 6 & 6 & 4 & 16 \\
\hline Haptoglobulin & 7 & 5 & 4 & 16 \\
\hline Caeruloplasmin & 7 & 6 & 3 & 16 \\
\hline C-reactive protein & 8 & 10 & 3 & 21 \\
\hline Serum amyloid protein $A$ & 12 & 9 & 4 & 25 \\
\hline Collagen & 34 & 3 & 1 & 38 \\
\hline Metallothionein & 11 & 13 & 32 & 56 \\
\hline \multicolumn{5}{|l|}{$\begin{array}{l}\text { Decreased synthesis during } \\
\text { inflammation }\end{array}$} \\
\hline Serum albumin & 3 & 5 & 7 & 15 \\
\hline Muscle (Whole) & 5 & 5 & 4 & 14 \\
\hline
\end{tabular}

Argiles et al. (1989b) observed rapid decreases in these same amino acids in rats, within $2.5 \mathrm{~h}$ of injection with IL $1 \beta$ and TNF $\alpha$. Klasing \& Barnes (1988) challenged chickens with bacterial endotoxins after they had been raised on diets containing either inadequate or sufficient amounts of methionine or lysine. They measured serum ILI concentrations and monitored cytokine-mediated changes by observing effects on serum zinc, iron and copper. Methionine insufficiency produced the most clearcut effects. Deficient birds had lower serum ILl concentrations, and did not experience as great a depression in serum $\mathrm{Zn}$ and elevation of serum $\mathrm{Cu}$, as those that were methionine replete. Lysine deficiency prevented the fall in serum $\mathrm{Zn}$, but had no effect on the elevation of $\mathrm{Cu}$ concentrations.

There is indirect evidence of increased glycine requirements in inflammatory states. Jackson et al. (1987) have suggested that elevated urinary excretion of 5-oxoproline (5-OP) is indicative of glycine insufficiency. Raised excretion has been noted in a number of disorders with inflammatory components, such as sepsis and rheumatoid arthritis. Moran 
et al. (1989) demonstrated a fourfold increase in S-OP in severely ill post-operative patients, the majority of which had severe sepsis. R. F. Grimble \& M. Wride (unpublished results) studied the modifying effects of alanine, glycine and cysteine supplementation, in isonitrogenous amounts, of diets containing $80 \mathrm{~g}$ casein $/ \mathrm{kg}$ on rats given TNF. While TNF was unable to increase hepatic $\mathrm{Zn}$ concentration in rats receiving the diet containing alanine, it caused an elevation of 31 and $32 \%$ in those receiving glycine- and cysteinecontaining diets. Liver total protein content was elevated in the rats receiving the cysteinecontaining diet to a greater extent than in those receiving diets containing glycine or alanine (36\% v. 20\% and $18 \%$ respectively). This may suggest that metallothionein synthesis is particularly sensitive to the availability of cysteine and glycine, and that cysteine is particularly important for hepatic protein anabolism during inflammation.

\section{Branched-chain amino acids and threonine}

Studies carried out by Fern et al. (1984) and Peck et al. (1989) suggest that dietary amino acid and protein sufficiency might affect the ability to produce cytokines. In the studies the effects of Plasmodium berghei malaria and peritonitis were examined respectively. Lethality in both conditions has been associated with TNF production (Clark, 1987; Grau et al. 1987; Cerami \& Beutler, 1988). It was noted that rats fed on a low-protein diet showed low levels of parasitaemia when infected with $P$. berghei. Significant increases in the levels of infection were obtained by supplementation of the diet with various combinations of amino acids. Threonine was the most effective particularly when in combination with valine, isoleucine and leucine (branched-chain amino acids; BCAA). One interpretation of this response, put forward by the authors, was that the amino acid supplements were satisfying the requirements of the parasites for multiplication. Examination of the findings shows a further phenomenon. Low-peak parasitaemias and mortalities occurred in diets containing all three BCAA, but not threonine. When threonine was included in the diet with one, two or all three BCAA the level of the parasitized cells rose. Mortalities, however, did not rise consistently in line with these changes. While additions of threonine, valine and isoleucine caused $34 \%$ of cells to be parasitized and a $25 \%$ mortality rate, addition of threonine, valine, isoleucine and leucine resulted in $30 \%$ of parasitized cells and $62 \%$ mortality. It is interesting to note that TNF comprises $10 \%$ leucine and a combined total of $26 \%$ of threonine, valine, isoleucine and leucine. If serine and glycine, which are metabolically related to threonine (Fig. 4), are included in the calculation then $41 \%$ of the amino acids in TNF are accounted for. Thus, the addition of specific amino acids may have allowed sufficient production of TNF to occur in rats on a diet which would otherwise suppress the ability for cytokine production. TNF is produced in milligram quantities in rabbits in response to endotoxin (Beutler \& Cerami, 1986). Whether similar quantities are produced in well fed rats during malaria in unknown. However, Bate et al. (1988) have reported that peritoneal macrophages of well fed mice are capable of producing substantial amounts of TNF $\alpha$ in response to $P$. berghei.

Peck et al. (1989) demonstrated that the lethality of E. coli and Staphylococcus aureus administered by osmotic minipump increased with the level of protein fed to guinea-pigs over a 2-week period. The level of protein, fed by gastric intubation, ranged from an inadequate $5 \%$ of total energy to a generous $20 \%$ of energy. Lethality ranged from 15 to $54 \%$ respectively.

\section{EFFECTS OF OVERNUTRITION}

In a second study, the same group (Alexander et al. 1989) examined the effects of overfeeding on lethality. Animals that received an adequate $523 \mathrm{~kJ}(125 \mathrm{kcal}) / \mathrm{kg}$ per d showed $62 \%$ mortality; however, those receiving 628 and $733 \mathrm{~kJ}(150$ and $175 \mathrm{kcal}) / \mathrm{kg}$ 
per $d$ had $100 \%$ mortality. The authors attributed the increased mortality to enhanced bacterial virulence. Since weight losses of 13 and $10 \%$ were observed in the groups receiving 628 and $733 \mathrm{~kJ} / \mathrm{kg}$ per d compared with $2 \%$ in animals receiving $523 \mathrm{~kJ} / \mathrm{kg}$ per d, increased cytokine production may have played a part in the enhanced lethality. This interpretation must, however, remain conjectural because circulating cytokine concentrations were not reported in either paper.

\section{EFFECTS OF VITAMINS AND MINERALS ON CYTOKINE PRODUCTION AND ACTIONS}

Multiple deficiencies of trace elements and vitamins are found in the elderly and among hospital patients who may be undergoing a chronic inflammatory process, and also in populations in which infections and infestations are rife. However, little work has been done on the effects of individual deficiencies on cytokine production or actions.

\section{RON}

It was noted by Winyard et al. (1987) that treatment of anaemic rheumatoid patients with Fe exacerbated inflammatory symptoms. While changes in free radical production may have contributed to this effect, studies with rats suggest that altered cytokine activity is also a possibility. Helyar \& Sherman (1987) showed that peritoneal macrophages, taken from severely Fe-deficient animals, had impaired abilities to produce cytokines. The bioassays used by these authors to quantify cytokine production, while suggesting that ILl production was changed, do not rule out alterations in IL6 or TNF $\alpha$. TNF has been shown to produce anaemia in man and rat. In the latter, a $46 \%$ decrease in erythrocyte mass occurred, which matched the fall in haemoglobin concentration. The mechanism of this effect is unclear. TNF $\alpha$, however, has been shown to inhibit haemopoetic precursor cell proliferation and expression of erythroid burst-forming units in vitro (Tracey et al. 1988; Pfreundschuh et al. (1989).

\section{COPPER AND ZINC}

Indirect evidence that $\mathrm{Cu}$ deficiency may reduce cytokine production comes from a study by Mulhern \& Koller (1988), in which mice receiving Cu-deficient diets showed only $64 \%$ of the normal increase in spleen cells when exposed to $E$. coli lipopolysaccharide (LPS). There is a growing body of evidence that deficiencies of $\mathrm{Cu}$ and $\mathrm{Zn}$ limit the ability of animals to raise concentrations of proteins rich in these trace elements. $\mathrm{Cu}$ deficiency also impairs the ability of rats to raise plasma caeruloplasmin $(E C 1.16 .3 .1)$ concentrations, when exposed to the double stress of endotoxin and high oxygen concentrations in inspired air. The ability of the dual stress to raise the concentrations of the antioxidant enzyme $\mathrm{Cu}-\mathrm{Zn}$ superoxide dismutase $(E C 1,15.1 .1)$ in lung was also impaired by $\mathrm{Cu}$ deficiency (Spence et al. 1986). Barber \& Cousins (1988) examined the effects of $\mathrm{Cu}$ deficiencies on the ability of ILI to induce caeruloplasmin in rats. While $\mathrm{Cu}$ deficiency per se had no effect on the ability to induce synthesis of the protein, the protein did not have full oxidase activity unless $\mathrm{Cu}$ was present in the diet. Huber \& Cousins (1988) demonstrated the ability of $\mathrm{Zn}$ deficiency to impair metallothionein at the transcriptional level in pregnant rats given ILI. In the study hepatic metallothionein mRNA and protein was not only depressed in mother and fetus, as the result of a low dietary $\mathrm{Zn}$ intake, but the ability to increase in response to an injection of ILl was also impaired. Bremner et al. (1987) demonstrated a similar phenomenon in the response of hepatic metallothionein to endotoxin in non-pregnant rats. 
While a ninefold increase occurred in $\mathrm{Zn}$-replete animals, only a threefold increase occurred in deficient animals.

\section{VITAMINS A AND E}

A multitude of studies have shown that vitamins are important in maintaining immune status (Gross \& Newberne, 1980). It is not clear, however, if cytokines play any part in this relationship. Vitamin $\mathrm{A}$ is particularly important in maintaining adequate cell-mediated immunity. Epidemiological studies indicate that the vitamin and other retinoids are important in resistance to infections and cancer (Vyas \& Chandra, 1984; Watson \& Leonard, 1986). Moriguchi et al. (1985) showed that when mice were given sixteen times the normal intake of vitamin A there was a doubling in the amount of IL1 that could be elicited from peritoneal macrophages by endotoxin stimulation.

Macrophages produce free radicals, in addition to cytokines, when stimulated by noxious agents such as endotoxin. Vitamin $E$ is acknowledged to be an antioxidant whose deficiency may lead to increased susceptibility to oxidative stress. Little work has, however, been performed on the importance of the vitamin in influencing the production and actions of cytokines. What work has been reported indicates that subtle modifications may occur (Omer et al. 1986, 1988). Millward et al. (1989) describe rat studies of the growth inhibition and particularly the catabolic response of muscle and loss of muscle glutamine associated with protein deficiency, vitamin E deficiency and endotoxaemia induced by the E. coli LPS. They report that while vitamin $E$ deficiency had little impact on the inhibition of muscle protein synthesis by LPS in otherwise well fed rats, in protein-deficient rats vitamin $\mathrm{E}$ deficiency did reduce the catabolic influence of LPS. In contrast, vitamin $\mathrm{E}$ deficiency tended to increase the loss of muscle glutamine in response to LPS. Thus, the striking relationship between changes in muscle glutamine and protein synthesis which these workers describe in response to LPS (and other catabolic insults: see Rennie et al. 1986) is changed by vitamin $\mathrm{E}$ deficiency, so that in the most extreme case reductions in muscle glutamine are not accompanied by any parallel reductions in protein synthesis. The authors point out that whilst these interactions between protein and vitamin $E$ deficiency and endotoxaemia are complex situations which have yet to be unravelled they do indicate that if the glutamine-protein synthesis changes in endotoxaemia are related, as would be indicated by the work of Rennie and coworkers (e.g. MacLennan et al. 1987), vitamin E deficiency reduces the sensitivity of the link so that changes in glutamine occur with no accompanying reductions in protein synthesis.

\section{FUTURE STUDIES}

The main impetus in the discovery and characterization of cytokines has undoubtedly been the hope that they may be useful in the enhancement of immune function. As a result much has been discovered about the immunological and metabolic actions of exogenously applied cytokines. These studies together with the development of assays which are sensitive in the picogram range have allowed some insight also to be obtained into the part played by cytokines in inflammatory disease. It is not known, however, whether each inflammatory condition results from a similar or a different profile of cytokines. This clearly is a major area for future investigations.

The observations that nutrients may influence the ability to produce and respond to cytokines could also be of major clinical relevance. In these situations it may be desirable to enhance or suppress cytokine production and/or actions. Nutritional manipulation may provide the means to achieve such an outcome. 
There are a number of important points about cytokine biology which should be considered when investigating these possibilities in animal and human studies. Doses of cytokines should be used which are physiologically meaningful. The significance of plasma concentration should be treated with caution, since there is a growing body of evidence that cytokines are rapidly cleared from the circulation. The likelihood that many cytokines are produced and act locally, i.e. through autocrine and/or paracrine mechanisms, makes it imperative that reliable methods are developed to observe these phenomena. The ability of one cytokine to induce production of another, and the likelihood that inflammatory diseases bring about production of a range of cytokines which may subsequently interact, means that care should be taken in interpreting the results of studies where single cytokines are administered. The use of monoclonal antibodies for cytokines will help in interpretation of findings from such studies. A better knowledge of nutrient-cytokine and cytokinecytokine interactions may also be important in situations where cytokines are currently being used therapeutically, such as in the treatment of cancer (Chapman et al. 1987; Kimura et al. 1987; Galvani, 1988; Rosenberg et al. 1988), and potentially in treating complications associated with acquired immunodeficiency syndrome (Ammann et al. 1987).

\section{REFERENCES}

Alexander, J. W., Gance, S. J., Miskell, P. W., Peck, M. D. \& Sax, H. (1989). A new model for studying nutrition in peritonitis; the adverse effect of overfeeding. Annals of Surgery 209, 334-340.

Alexander, J. W., Saito, H., Trocki, O. \& Ogle, C. K. (1986). The importance of lipid type in the diet after burn injury. Annals of Surgery 204, 1-8.

Alleyne, G. A. O., Hay, R. W., Picou, D. I., Stanfield, J. P. \& Whitehead, R. G. (1977). Protein-Energy Malnutrition. London: Edward Arnold.

Ammann, A. J., Palladino, M. A., Volberding, P., Abrams, D., Martin, N. L. \& Conant, M. (1987). Tumour necrosis factor $\alpha$ and $\beta$ in acquired immunodeficiency syndrome (AIDS) and AIDS-related complex. Journal of Clinical Immunology 7, 481-485.

Andus, T., Geiger, T., Hirano, T., Kishimoto, T. \& Heinrich, P. C. (1988). Action of recombinant human interleukin 6 , interleukin $1 \beta$ and tumor necrosis factor $\alpha$ on the messenger RNA induction of acute phase proteins. European Journal of Immunology 18, 739-746.

Argilés, J. M., Lopez-Soriano, F. J., Evans, R. D. \& Williamson, D. H. (1989a). Interleukin-1 and lipid metabolism in the rat. Biochemical Journal 259, 673-678.

Argilés, J. M., Lopez-Soriano, F. J., Wiggins, D. \& Williamson, D. H. (1989 b). Comparative effects of tumour necrosis factor $\alpha$ (cachectin), interleukin $1 \beta$ and tumour growth on amino acid metabolism in the rat in vivo. Absorption and tissue uptake of $\alpha$-amino[ $\left.1-^{14} \mathrm{C}\right]$ isobutyrate. Biochemical Journal 261, 357.362.

Bagby, G. J., Lang, C. H., Hargrove, D. M., Thompson, J. J., Wilson, L. A. \& Spitzer, J. J. (1988). Glucose kinetics in rats infused with endotoxin-induced monokines or tumor necrosis factor. Circulatory Shock 24, $111-121$.

Barber, E. F. \& Cousins, R. J. (1988). Interleukin-1 stimulated induction of ceruloplasmin synthesis in normal and copper-deficient rats. Journal of Nutrition 118, 375-381.

Bate, C. A. W., Taverne, J. \& Playfair, J. H. L. (1988). Malarial parasites induce TNF production by macrophages. Immunology 64, 227--231.

Beutler, B. \& Cerami, A. (1986). Cachectin and tumour necrosis factor as two sides of the same biological coin. Nature 320, 584-588.

Beutler, B. \& Cerami, A. (1987). Cachectin tumor necrosis factor: a cytokine that mediates injury initiated by invasive parasites. Parasitology Today 3, 345-346.

Beutler, B. \& Cerami, A. (1988 a). Cachectin (tumor necrosis factor): a macrophage hormone governing cellular metabolism and inflammatory response. Endocrine Reviews 9, 57-66.

Beutler, B. \& Cerami, A. (1988 b). Cachectin, cachexia, and shock. Annual Review of Medicine 39, $75-83$.

Bhaskaram, P. \& Sivakumar, B. (1986). Interleukin-1 in malnutrition. Archives of Disease in Childhood 61, $182-185$.

Bibby, D. C. \& Grimble, R. F. (1990a). Dietary fat modifies some metabolic actions of human tumour necrosis factor $\alpha$ in rats. British Journal of Nutrition 63, 653-668.

Bibby, D. C. \& Grimble, R. F. $(1990 \mathrm{~b})$. Tumour necrosis factor $\alpha$ and endotoxin induce less prostaglandin $\mathrm{E}_{2}$ production from hypothalami of rats fed coconut than maize oil. Clinical Science In the press.

Bittiner, S. B., Tucker, W. F. G., Cartwright, I. \& Bleehen, S. S. (1988). A double-blind, randomised, placebocontrolled trial of fish oil in psoriasis. Lancet i, 378-380. 
Bochner, B. S.. Rutledge, B. K. \& Schleimer, R. P. (1987). Interleukin 1 production by human lung tissue. II. Inhibition by anti-inflammatory steroids. Journal of Immunology 139, 2302-2307.

Bremner, I., Morrison, J. N. \& Wood, A. M. (1987). Metallothionein levels in blood cells and urine of zincdeficient and endotoxin-treated rats. Proceedings of the Nutrition Society 46, 57A.

Brown, G., Hunt, V., Wan, J. \& Grimble, R. F. (1987). The differing responses of zinc and protein metabolism to Escherichia coli endotoxin in rats fed on diets containing maize, coconut and fish oils. Proceedings of the Nutrition Society 46, 36A.

Cannon, J. G. \& Dinarello, C. A. (1985). Increased plasma interleukin-1 activity in women after ovulation. Science 227, 1247-1249.

Cannon, J. G., Fielding, R. A., Fiatarone, M. A., Orencole, S. F., Dinarello, C. A. \& Evans, W. J. (1989). Increased interleukin $1 \beta$ in human skeletal muscle after exercise. American Journal of Physiology 257, R451-R456.

Cannon, J. G. \& Kluger, M. J. (1983). Endogenous pyrogen activity in human plasma after exercise. Science 220. $617-619$.

Castell, J. V., Andus, T., Kunz, D. \& Heinrich, P. C. (1989). Interleukin 6. The major regulator of acute phase protein synthesis in man and rat. Annals of the New York Academy of Sciences 557, 87-101.

Cerami, A. \& Beutler, B. (1988). The role of cachectin/TNF in endotoxic shock and cachexia. Immunology Today: 9, 28-31

Cerra, F. B., Alden, P. A., Negro, F., Billion, T., Svingen, B. A., Licari, J., Johnson, B. S. \& Holman, R. T. (1988). Sepsis and exogenous lipid modulation. Journal of Parenteral and Enteral Nutrition 12, 635685.

Cinapman, P. B., Lester, T. J., Casper, E. S., Gabrilove, J. L., Wong, G. Y., Kempin, S. J., Gold, P. J., Welt, S., Warren, R. S., Starnes, H. F., Sherwin, S. A., Old, I. J. \& Oettgen, H. F. (1987). Clinical pharmacology of recombinant human tumor necrosis factor in patients with advanced cancer. Journal of Clinical Oncology $\mathbf{5}$, 1942-1951.

Charters, Y. \& Grimble, R. F. (1989). Effect of recombinant human tumour necrosis factor $\alpha$ on protein synthesis in liver, skeletal muscle and skin of rats. Biochemical Journal 258, 493497.

Clark, I. A. (1987). Cell-mediated immunity in protection and pathology of malaria. Parasitology Today 3, 300-305.

Cousins, R. J. \& Leinart, A. S. (1988). Tissue specific regulation of zinc metabolism and metallothionein genes by interleukin 1. FASEB Journal 2, 2884-2890.

Dao, T. K., Bell, R. C., Feng, J., Jameson, D. M. \& Lipton, J. M. (1988). C-reactive protein, leukocytes, and fever after central ILl and $\alpha$-MSH in aged rabbits. American Journal of Physiology 254, R401-R409.

Del Rey, A., Besedovsky, H., Sorkin, E. \& Dinarello, C. A. (1987). Interleukin-1 and glucocorticoid hormones integrate an immunoregulatory feedback circuit. Annals of the New York Academy of Sciences 496, 85-90.

Dinarello, C. A. (1984a). Interleukin-1 and the pathogenesis of the acute-phase response. New England Journal of Medicine 311, 1413-1417.

Dinarello, C. A. (1984 b). Interleukin-1. Review of Infectious Diseases 6, 51-95.

Dinarello, C. A. (1986) Multiple biological properties of recombinant human interleukin 1 (beta). Immunobiology 172, 301-315.

Dinarello, C. A. (1987). The biology of interleukin 1 and comparison to tumor necrosis factor. Immunology Letters 16, 227-232.

Dinarello, C. A., Bishai, I., Rosenwasser, L. J. \& Coceani, F. (1984). The influence of lipoxygenase inhibitors on the in vitro production of human leukocytic pyrogen and lymphocyte activating factor (interleukin 1). International Journal of Immunopharmacology 6, 43-50.

Dinarello, C. A., Cannon, J. G. \& Wolf, S. M. (1988). New concepts on the pathogenesis of fever. Review of Infectious Diseases 10, 168-189.

Dinarello, C. A., Cannon, J. G., Wolff, S. M., Bernheim, H. A., Beutler, B., Cerami, A., Figari, I. S., Palladino, M. A. \& O'Connor, J. V. (1986). Tumor necrosis factor (cachectin) is an endogenous pyrogen and induces production of interleukin 1. Journal of Experimental Medicine 163, 1433 - 1450.

Douglas, R. G. \& Shaw, J. H. F. (1989). Metabolic response to sepsis and trauma. British Journal of Surgery 76, 115-122.

Endres, S., Ghorbani, R., Kelley, V. E., Georgilis, K., Lonnemann, G., Van der Meer, J. W. M., Cannon, J. G., Rogers, T. S., Klempner, M. S., Weber, P. C., Schaeffer, E. J., Wolff, S. M. \& Dinarello, C. A. (1989). The effect of dietary supplementation with n-3 polyunsaturated fatty acids on the synthesis and ILl and TNF $\alpha$ by mononuclear cells. New England Journal of Medicine 320, 266-271.

Evans, R. D. \& Williamson, D. H. (1988). Tumour necrosis factor $\alpha$ (cachectin) mimics some of the effects of tumour growth on the disposal of a $\left[{ }^{14} \mathrm{C}\right]$ lipid load in virgin, lactating and litter-removed rats. Biochemical Journal 256, 10551058.

Evans, R. D., Argilés, J. M. \& Williamson, D. H. (1989). Metabolic effects of tumour necrosis factor- $\alpha$ (cachectin) and interleukin 1. Clinical Science 77, 35764.

Feingold, K. R., Serio, M. K., Adi, S., Moser, A. H. \& Grunfeld, C. (1989). Tumor necrosis factor stimulates hepatic lipid synthesis and secretion. Endocrinology 124, 2336-2342. 
Fern, E. B., Edirisinghe, J. S. \& Targett, G. A. T. (1984). Increased severity of malaria infection in rats fed supplementary amino acids. Transactions of the Royal Society of Tropical Medicine 78, 839. 841.

Flores, E. A., Bistrian, B. R., Pomposelli, J. J., Dinarello, C. A., Blackburn, G. L. \& Istfan, N. W. (1989). Infusion of tumor necrosis factor/cachectin promotes muscle catabolism in the rat: a synergistic effect with interleukin 1. Journal of Clinical Investigation 83, 16141622.

Fong, Y., Moldawer, L. L., Marano, M., Wei, H., Barber, A., Manogue, K., Tracey, K. J., Kuo, G., Fischman, D. A., Cerami, A. \& Lowry, S. F. (1989). Cachectin/TNF or IL-1 $\alpha$ induces cachexia with redistribution of body proteins. American Journal of Physiology 256, R659 R665.

Fung, K. P., Cheng, C. P., Luey, L. U., Loh, S. C., Choy, Y. M. \& Lee, C. Y. (1988). Effect of combined treatment of anti-inflammatory drug and mannoheptulose on the production of tumour necrosis factor and endotoxin shock in mice. Cancer Letters 39, 137-143.

Galvani, D. W. (1988). Cytokines : biological function and clinical use. Journal of the Royal College of Physicians 22, 226231 .

Grau, G. E., Fajardo, L. F., Piguet, P. F., Allet, B., Lambert, P. H. \& Vassalli, P. (1987). Tumor necrosis factor (cachectin) is an essential mediator in murine cerebral malaria. Science 237, 1210-1212.

Grimble, R. F. (1989). Cytokines: their relevance to nutrition. European Journal of Clinical Nutrition 43, 217230.

Gross, R. L. \& Newberne, P. M. (1980). Role of nutrition in immunologic function. Physiological Reviews 60 , $188-302$.

Guerne, A. P., Zuraw, B. L., Vaughan, J. H., Carson, D. A. \& Lotz, M. (1989). Synovium as a source of interleukin 6 in vitro. Journal of Clinical Investigation 83, 585-592.

Heinrich, P. C., Castell, J. V. \& Andus, T. (1990). Interleukin-6 and the acute phase response. Biochemical Journal 265, 621-636.

Helyar, L. \& Sherman, A. R. (1987). Iron deficiency and interleukin I production by rat leukocytes. American Journal of Clinical Nutrition 46, 346-352.

Holtmann, H. \& Wallach, D. (1987). Down regulation of the receptors for tumor necrosis factor by interleukin 1 and 4- $\beta$-phorbol-12-myristate-13-acetate. Journal of Immunology 139, 1161-1167.

Huber, K. L.\& Cousins, R. J. (1988). Maternal zinc deprivation and interleukin-1 influence metallothionein gene expression and zinc metabolism of rats. Journal of Nutrition 118, 1570-1576.

Hutson, S. M., Stinson-Fisher, C., Shiman, R. \& Jefferson, L. S. (1987). Regulation of albumin synthesis by hormones and amino acids in primary cultures of rat hepatocytes. American Journal of Physiology 252, E291-E298.

Hwang, D. (1989). Essential fatty acids and immune response. FASEB Journal 3, 2052-2061.

Jackson, A. A., Badaloo, A. V., Forrester, T., Hibbert, J. M. \& Persaud, C. (1987). Urinary excretion of 5oxoproline (pyroglutamic aciduria) as an index of glycine insufficiency in normal man. British Journal of Nutrition 58, 207-214.

Jeevanandam, M.. Young, D. H., Ramias L. \& Schiller, W. R. (1989). Aminoaciduria of severe trauma. American Journal of Clinical Nutrition 49, 814-822.

Kauffman, C. A.. Jones, P. G. \& Kluger, M. J. (1986). Fever and malnutrition: endogenous pyrogen/interleukin1 in malnourished patients. American Journal of Clinical Nutrition 44, 449-452.

Keenan, R. A., Moldawer, L. L., Yang, R. D., Kawamura, I., Blackburn, G. L. \& Bistrian, B. R. (1982). An altered response by peripheral leukocytes to synthesize or release leukocyte endogenous mediator in critically ill, protein-malnourished patients. Journal of Laboratory and Clinical Medicine 100, 844 857.

Kimura, K., Taguchi, T., Urushizaki, I., Ohno, R., Abe, O., Furue, H., Hattori, T., Ichihashi, H., Inoguchi, K., Majima, H., Nijtani, H., Ota, K., Saito, T., Suga, S., Suzuoki, Y., Wakui, A. \& Yamada, K. (1987). Phase I study of recombinant human tumor necrosis factor. Cancer Chemotherapy and Pharmacology 20, 223-229.

Klasing, K. C. \& Barnes, D. M. (1988). Decreased amino acid requirements of growing chicks due to immunologic stress. Journal of Nutrition 118, 1158-1164.

Kremer, J. M., Jubiz, W., Michalek, A., Rynes, R. I., Bartholomew, L. E., Bigaouette, J., Timchalk, M., Beeler, D. \& Lininger, L. (1987). Fish-oil fatty acid supplementation in active rheumatoid arthritis: a double-blinded, placebo-controlled, cross-over study. Annals of Internal Medicine 106, 497-502.

Larrick. J. W. \& Kunkel, S. L. (1988). The role of tumor necrosis factor and interleukin 1 in the immunoinflammatory response. Pharmaceutical Research 5, 129.139.

Le, J., Weinstein, D., Gubler, U. \& Vilček, J. (1987). Induction of membrane-associated interleukin $\downarrow$ by tumor necrosis factor in human fibroblasts. Journal of Immunology 138, 2137-2142.

Liao, Z. \& Rosenstreich, D. L. (1983). An interleukin-1 inhibitor in the urine of febrile patients. Clinical Research 31, 492A.

Liu, M.-S. \& Zhang, J.-N. (1985). Glycolytic and tricarboxylic acid cycle intermediates in dog livers during endotoxic shock. Biochemical Medicine 34, 335-343.

MacLennan, P. A., Brown, R. A. \& Rennie, M. J. (1987). A positive relationship between protein synthetic rate and intracellular glutamine concentration in perfused rat skeletal muscle. FEBS Letters 215, $187-191$.

McCarthy, D. O., Kluger, M. J. \& Vander, A. J. (1984). The role of fever in appetite suppression after endotoxin administration. American Journal of Clinical Nutrition 40,310-316. 
Mahida, Y. R., Wu, K. \& Jewell, D. P. (1989). Enhanced production of interleukin 1- $\beta$ by mononuclear cells isolated from mucosa with active ulcerative colitis of Crohn's disease. Gut 30, 835-838.

Mészáros, K., Lang, C. H., Bagby, G. J. \& Spitzer, J. J. (1987). Contribution of different organs to increased glucose consumption after endotoxin administration. Journal of Biological Chemistry 262, 10965-10970.

Millward, D. J., Jepson, M. M. \& Omer, A. (1989). Muscle glutamine concentration and protein turnover in vivo in malnutrition and in endotoxemia. Metabolism 38, Suppl. 1, 6-13.

Miossec, P. \& Ziff, M. (1986). Immune interferon enhances the production of interleukin 1 by human endothelial cells stimulated with lipopolysaccharide. Journal of Immunology 137, 2848-2852.

Moldawer, L. L., Svaninger, G., Gelin, J. \& Lundholm, K. G. (1987). Interleukin 1 and tumor necrosis factor do not regulate protein balance in skeletal muscle. American Journal of Physiology 253, C766-C773.

Moran, B., Persaud, C. \& Jackson, A. A. (1989). Urinary excretion of 5-oxoproline in severe inflammatory illness. Proceedings of the Nutrition Society 48, 75A.

Moriguchi, S., Werner, L. \& Watson, R. R. (1985). High dietary vitamin A (retinyl palmitate) and cellular immune functions in mice. Immunology 56, 169-177.

Mortensen, R. F., Shapiro, J., Lin, B.-F., Douches, S. \& Neta, R. (1988). Interaction of recombinant IL-I and recombinant tumor necrosis factor in the induction of mouse acute phase proteins. Journal of Immunology 140 , 2260-2266.

Mulhern, S. A. \& Koller, L. D. (1988). Severe or marginal copper deficiency results in a graded reduction in immune status in mice. Journal of Nutrition 118, 1041-1047.

Neta, R., Vogel, S. N., Sipe, J. D., Wong, G. G. \& Nordan, R. P. (1988). Comparison of in vivo effects of human recombinant IL 1 and human recombinant IL 6 in mice. Lymphokine Research 7, 403-412.

Neumann, C. G., Lawlor, G. J., Stiehm, E. R., Swendseid, M. E., Newton, C., Herbert, J., Ammann, A. J. \& Jacob, M. (1975). Immunologic responses in malnourished children. American Journal of Clinical Nutrition 28. 89-104.

Newsholme, E. A., Crabtree, B. \& Ardawi, M. S. M. (1985). Glutamine metabolism in lymphocytes: its biochemical, physiological and clinical importance. Quarterly Journal of Experimental Physiology 70, $473-489$.

Newsholme, P. \& Newsholme, E. A. (1989). Rates of utilization of glucose, glutamine and oleate and formation of end-products by mouse peritoneal macrophages in culture. Biochemical Journal 261, 211218.

Old, L. J. (1987). Polypeptide mediator network. Nature 326, 330-331.

Omer, A. B., Bates, P. C. \& Millward, D. J. (1986). Response of the vitamin-E-deficient rat to severe protein deficiency and the Escherichia coli endotoxin. Proceedings of the Nutrition Society 45, 114A.

Omer, A. B., Bates, P. C. \& Millward, D. J. (1988). Effect of combined vitamin E and protein deficiency on the hepatic response of the rat to the Escherichia coli endotoxin. Proceedings of the Nutrition Society 47, 10A.

Patton, J. S., Peters, P. M., McCabe, J., Crase, D., Hansen, S., Chen, A. B. \& Liggit, D. (1987). Development of partial tolerance to the gastrointestinal effects of recombinant tumor necrosis factor- $\alpha$ in rodents. Journal of Clinical Investigation 80, 1587-1596.

Peck, M. D., Alexander, J. W., Gonce, S. J. \& Miskell, P. W. (1989). Low protein diets improve survival from peritonitis in guinea pigs. Annals of Surgery 209, 448- 454.

Pfreundschuh, M. G., Steinmetz, H. T., Tuschen, R., Schenk, V., Diehl, V. \& Schaadt, M. (1989). Phase I study of intratumoral application of recombinant human tumor necrosis factor. European Journal of Cancer and Clinical Oncology 25, 379-387.

Plata-Salamán, C. R., Oomura, Y. \& Kai, Y. (1988). Tumor necrosis factor and interleukin $1 \beta$; suppression of food intake by direct action in the central nervous system. Brain Research 448, 106114.

Ramadori, G., VanDamme, J., Rieder, H. \& Meyer zum Buschenfelde, K. H. (1988). Interleukin-6, the third mediator of acute-phase reaction, modulates hepatic protein synthesis in human and mouse. Comparison with ILI $\beta$ and TNF $\alpha$. European Journal of Immunology 18, 1259. 1264.

Rennie, M. M., Hundal, H. S., Babij, P., MacLennan, P., Taylor, P. M., Watt, P. W., Jepson, M. M. \& Millward, D. J. (1986). Characteristics of a glutamine carrier in skeletal muscle have important consequences for nitrogen loss in injury, infection, and chronic disease. Lancet ii, 1008-1012.

Revhaug, A., Michie, H. R., Manson, J. McK., Watters, J. M., Dinarello, C. A., Wolf, S. M. \& Wilmore, D. W. (1988). Inhibition of cyclo-oxygenase attenuates the metabolic response to endotoxin in humans. Archives of Surgery 123, 162-170.

Rogers, T. S., Halushka, P. V., Wise, W. C. \& Cook, J. A. (1989). Arachidonic acid turnover in peritoneal macrophages is altered in endotoxin-tolerant rats. Biochimica et Biophysica Acta 1001, 169-175.

Rola-Pleszczynski, M. \& Lemaire, I. (1985). Leukotrienes augment interleukin I production by human monocytes. Journal of Immunology 135, 3958-3961 .

Rosenberg, S. A., Lotze, M. T. \& Mulé, J. J. (1988). New approaches to the immunotherapy of cancer using interleukin 2. Annals of Internal Medicine 108, 853-864.

Rothwell, N. J. (1989). CRF is involved in the pyrogenic and thermogenic effects of interleukin $1 \beta$ in the rat. American Journal of Physiology 256, E111-115.

Sherry, B. \& Cerami, A. (1988). Cachectin/tumor necrosis factor exerts endocrine, paracrine, and autocrine control of inflammatory responses. Journal of Cellular Biology 107, 1269-1277. 
Spence, T. H., Jenkinson, S. G., Johnson, K. H., Collins, J. F. \& Lawrence, R. A. (1986). Effects of bacterial endotoxin in protecting copper-deficient rats from hyperoxia. Journal of Applied Physiology 61, 982-987.

Spinas, G. A., Mandrup-Poulsen, T., Mølvig, J, Baek, L., Bendtzen, K., Dinarello, C. A. \& Nerup, J. (1986). Low concentrations of interleukin-1 stimulate and high concentrations inhibit insulin release from isolated rat islets of Langerhans. Acta Endocrinologia 113, 551-558.

Staruch, M. J. \& Wood, D. D. (1985). Reduction of serum interleukin-1-like activity after treatment with dexamethasone. Journal of Leukocyte Biology 37, 193-207.

Tracey, K. J., Wei, H., Manogue, K. R., Fong, Y., Hesse, D. G., Nguyen, H. T., Kuo, G. C., Beutler, B., Cotran, R. S., Cerami, A. \& Lowry, S. F. (1988). Cachectin/tumor necrosis factor induces cachexia, anemia, and inflammation. Journal of Experimental Medicine 167, 1211-1227.

Trocki, O., Heyd, T. J., Waymack, J. P. \& Alexander, J. W. (1987). Effects of fish oil on postburn metabolism and immunity. Journal of Parenteral and Enteral Nutrition 11, 521-528.

Uehara, A., Gottschall, P. E., Dahl, R. R. \& Arimura, A. (1987). Interleukin-1 stimulates ACTH release by an indirect action which requires endogenous corticotropin releasing factor. Endocrinology 121, 1580-1582.

Uehara, A., Sekiya, C., Takasugi, Y., Namiki, M. \& Arimura, A. (1989). Anorexia induced by interleukin 1: involvement of corticotropin-releasir.g factor. American Journal of Physiology 257, R613-R617.

Unglaub, R., Maxeiner, B., Thoma, B., Pfizenmaier, K. \& Scheurich, P. (1987). Downregulation of tumor necrosis factor (TNF) sensitivity via modulation of TNF binding capacity by protein kinase C activators. Journal of Experimental Medicine 166, 17881797.

Van der Meer, J. W. M., Endres, S., Lonnemann, G., Cannon, J. G., Ikejima, T., Okusawa, S., Gelfand, J. A. \& Dinarello, C. A. (1988). Concentrations of immunoreactive human tumor necrosis factor alpha produced by human mononuclear cells in vitro. Journal of Leukocyte Biology 43, 216-223.

Vyas, D. \& Chandra, R. K. (1984). Vitamin A and immunocompetence. In Nutrition, Disease Resistance and Immune Function, pp. 325-356 [R. R. Watson, editor]. New York: Marcel Dekker.

Waage, A., Halstensen, A. \& Espevik, T. (1987). Association between tumour necrosis factor in serum and fatal outcome in patients with meningococcal disease. Lancet i, 355-357.

Wan, J. M. \& Grimble, R. F. (1987). Effect of dietary linoleate content on the metabolic response of rats to Escherichia coli endotoxin. Clinical Science 72, 383-385.

Wan, J. M., Teo, T. C., Babagon, V. K. \& Blackburn, G. L. (1988). Lipids and the development of immune dysfunction and infection. Journal of Parenteral and Enteral Nutrition 12, 435-485.

Wannemacher, R. W. (1977). Key role of various individual amino acids in host response to infection. American Journal of Clinical Nutrition 30, 1269-1280.

Warner, S. J. C., Auger, K. R. \& Libby, P. (1987). Interleukin 1 induces interleukin 1. II. Recombinant human interleukin 1 induces interleukin 1 production by adult human vascular endothelial cells. Journal of Immunology 139, $1911-1917$.

Watson, R. R. \& Leonard, T. K. (1986). Selenium and vitamins A, E and C: nutrients with cancer prevention properties. Journal of the American Dietetic Association 86, 505-510.

Winyard, P. G., Blake, D. R., Chirico, S., Gutteridge, J. M. C. \& Lunec, J. (1987). Mechanism of exacerbation of rheumatoid synovitis by total-dose iron-dextran infusion: in vivo demonstration of iron-promoted oxidant stress. Lancet i, 69-72. 